\title{
Potent effects of alkaloid-rich extract from Huperzia selago against sodium nitroprusside-evoked PC12 cells damage via attenuation of oxidative stress and apoptosis
}

\author{
Anna Magdalena Lenkiewicz ${ }^{1}$, Grzegorz Arkadiusz Czapski ${ }^{1}$, Henryk Jęsko ${ }^{1}$, Anna Wilkaniec ${ }^{1}$, Wojciech Szypuła ${ }^{2}$, \\ Agnieszka Pietrosiuk ${ }^{2}$, Aneta Marta Uszyńska ${ }^{1}$, Agata Adamczyk $^{1}$ \\ ${ }^{1}$ Mossakowski Medical Research Centre, Polish Academy of Sciences, Warsaw, ${ }^{2}$ Medical University of Warsaw, Poland
}

\begin{abstract}
Imbalance between production and scavenging of free radicals and other reactive oxygen species (ROS) is a component of many diseases, but it is especially important in aging-related diseases of the central nervous system. Oxidative stress-induced neuronal dysfunction plays an important role in the pathomechanism of neurodegenerative disorders, including Alzheimer's and Parkinson's disease. Experimental data showed that free radical scavengers may protect the brain against oxidative modifications. The need for efficient and safe antioxidants with therapeutic potential stimulated the rise of interest in the medicinal plant products, which are a rich source of phytochemicals possessing biological activity. In our studies we focused on alkaloid fractions (AFs) isolated from club moss, Huperzia selago and Diphasiastrum complanatum, due to their beneficial activity and exclusive chemical structure. Our previous study demonstrated that selected alkaloids from Huperzia selago effectively protect macromolecules from oxidative damage. Therefore, in the present study we investigated the effects and mechanisms of action of AFs isolated from Huperzia selago and Diphasiastrum complanatum against sodium nitroprusside (SNP)-induced oxidative injury in PC12 cells. The results demonstrated that the selected AFs via reduction of nitric oxide (NO) liberation protected cells against oxidative stress, DNA and mitochondrial damage, as well as apoptosis caused by SNP. Selected AF notably decreased SNP-evoked mitochondrial polymerase $\gamma$ (Polg) up-regulation. Furthermore, AF which contains Lycopodine, Serratidine, Lycoposerramine-G and (probably) Cermizine B completely inhibited the SNP-induced expression of interferon- $\gamma$ (Ifng) and cyclooxygenase 2 (Ptgs2) as well as significantly down-regulated the expression of 12/15-lipoxygenase (Alox12) and tended to decrease the mRNA level of interleukin-6 gene (II6). In conclusion, these results suggest that the AFs from Huperzia selago effectively protect PC12 cells against SNP-induced oxidative damage by adjusting the level of reactive nitrogen species, suppression of apoptosis and down-regulation of proinflammatory genes. The compounds present in these AFs could be potential candidates to develop successful drugs preventing oxidative damage and apoptosis in age-related neurodegenerative disorders.
\end{abstract}

Key words: oxidative stress, apoptosis, cell death, cytoprotection, Huperzia selago, Diphasiastrum complanatum. 


\section{Introduction}

Oxidative stress is an important component of pathophysiology of countless human diseases, but it is especially important in the pathomechanism of neurodegenerative disorders, such as Alzheimer's (AD) and Parkinson's (PD) disease, multiple sclerosis (MS), amyotrophic lateral sclerosis (ALS) and other age-related diseases [15]. Neuronal cells need large amounts of ATP for maintaining a high rate of metabolic activity, and they pay a high price for their extraordinary energy demand - they are highly vulnerable to oxidative stress [19]. Neurons are, comparing with other cell types, mostly dependent on oxidative phosphorylation as an energy source, therefore they are exposed to high oxygen concentration. Moreover, neuronal cells are rich in polyunsaturated fatty acids (PUFA) that are prone to oxidation [2]. In addition, brain contains relatively poor mechanisms of antioxidant defense, for example low levels of catalase and glutathione peroxidase [32]. Neurons are enriched in metal ions, which accumulate in the brain during aging and may catalyze reactive oxygen species (ROS) formation [31]. Therefore, it is suggested that oxidative stress that increases during brain aging is an important factor making the aged brain especially susceptible to neurodegenerative processes [8]. Excessive generation of ROS is responsible for macromolecules modification, including lipid peroxidation, as well as protein and DNA oxidation which in consequence could lead to activation of apoptotic signaling and cell death [29]. Furthermore, oxidative stress is a deleterious process that can affect cellular $\mathrm{Ca}^{2+}$ homeostasis, composition of cellular membranes and mitochondria function. Moreover, oxidative stress is a factor stimulating protein misfolding in neurodegenerative diseases, it can trigger and/or accelerate aggregation of amyloid $\beta$ peptides (A $\beta$ ) and $\alpha$-synuclein (ASN) [38] that are critical in the pathogenesis of $A D$ and $P D$, respectively. Accumulating data suggest that antioxidant supplementation may be effective in the prevention and treatment of neurodegenerative diseases $[28,30]$ and several natural compounds with antioxidant properties are being investigated for treatment of $A D$ and PD. Some natural products including quercetin [4], curcumin [10], caffeic acid [12] and resveratrol [14] have been shown to be neuroprotective against oxidative injury. In addition, the antioxidant activities of various alkaloids, like berberine and huperzine $A$, have been investigated $[33,40]$ and it has been shown that early, regular usage of phytochemicals and their derivatives can delay the onset and progression of $A D$ [16]. Huperzia selago (L) Bernh. ex Schrank et Mart., a source of huperzine A (HupA) and other alkaloids commonly known as fir club moss (family Huperziaceae), is a plant of great interest that is used in combating a wide variety of diseases in European and Asian countries [5,22,36]. Plants of the Diphasiastrum complanatum (L) Holub (Lycopodiaceae sensu stricto) do not contain HupA but they are rich in alkaloids, mostly lycopodine and its derivatives [7]. Our previous in vitro studies have shown that some alkaloids of $H$. selago exhibit potent antioxidative properties, scavenge free radicals and prevent lipid and protein oxidation [7]. However, the cytoprotective activity of these extracts against ROS-induced cell damage has never been studied. Therefore, in this study, we analyzed whether alkaloid fractions (AFs) isolated from $H$. selago and $D$. complanatum may protect cells against ROS-evoked death and what mechanism may be responsible for protective effects of AFs. Sodium nitroprusside (SNP) was used to induce oxidative stress in rat pheochromocytoma PC12 cells. This cell line exhibits unique sensitivity to oxidants and is widely used as a cellular model to study the mechanisms of oxidative stress and apoptosis, as well as a model for studying antioxidative and cytoprotective properties of various antioxidants $[24,39,41]$. For example, studies on $\mathrm{PC} 12$ cells have shown that amyloidogenic proteins, $A \beta$ and ASN induce cytotoxicity and also elicit excessive free radical production $[1,11,18]$, mitochondrial dysfunction [11], apoptosis and cell death [20]. Here, we demonstrate that AFs prevent or at least markedly attenuate SNP-induced oxidative stress and protect PC12 cells from ROS-induced injury.

\section{Material and methods \\ Chemicals}

LDH-cytotoxicity Assay Kit II was purchased from BioVision (Mountain View, CA, USA), APO-DIRECT kit from BD Biosciences (San Jose, CA, USA), Dulbecco's Modified Eagle's Medium (DMEM), Fetal Bovine Serum (FBS), Horse Serum (HS), penicillin, streptomycin, glutamine, deoxyribonuclease I, 3-(4,5-dimehyl-2-tiazolilo)-2,5-diphenyl-2H-tetrazolium bromide (MTT), Hoechst 33342, DTT, polyethylenoimine (PEI), Pluronic, dimethyl sulfoxide (DMSO), TRI-reagent, DNAse I and all other common reagents were from 
Sigma-Aldrich (St. Louis, MO, USA). High Capacity cDNA Reverse Transcription Kit and TaqMan Gene Expression Master Mix were from Applied Biosystems (Foster City, CA, USA). DAF-2 DA was purchased from Cayman Chemical Company (Michigan, USA). Fluo-4 AM and Rhod-2 AM was purchased from Thermo Fischer Scientific Inc. HPLC grade water was purchased were from Merck KGaA, Darmstadt, Germany. Huperzine A was purchased from ChromaDex, Inc. (Laguna Hills, CA). The reference compounds, lycopodine and annotinine, were obtained from the Department of Pharmacognosy and Molecular Basis of Phytotherapy, Medical University of Warsaw.

\section{Preparation of alkaloid fractions (AFs)}

\section{Plant material}

Aerial parts of $H$. selago were collected in The Babia Gora Biosphere Reserve (Poland) in September 2010. Aerial parts of $D$. complanatum were collected in The Masurian Lake District (Poland). Material was identified and authenticated by one of the authors. Voucher specimens have been deposited in the herbarium of the Department of Pharmaceutical Biology and Medicinal Plant Biotechnology, Medical University of Warsaw.

\section{Preparation and extracts purification}

Alkaloid fractions were obtained by a conventional procedure from $\mathrm{MeOH}$ extract and examined using TLC and HPLC-DAD as previously reported by Czapski et al. [7].

\section{Preparation of standard and sample solution of alkaloids}

Standard solutions of HupA, lycopodine and annotinine as well as isolated AFs were dissolved in DMSO at a concentration $25 \mathrm{mg} / \mathrm{ml}$ which roughly corresponds to molar concentration of approximately $100 \mathrm{mM}$ for this group of alkaloids. Then dilutions were prepared in the same DMSO concentration, and AFs were used in final concentrations of $0.25 \mu \mathrm{g} /$ $\mathrm{ml}$ (approximately $1 \mu \mathrm{M}$ ), $2.5 \mu \mathrm{g} / \mathrm{ml}$ (approximately $10 \mu \mathrm{M})$ and $6.25 \mu \mathrm{g} / \mathrm{ml}$ (approximately $25 \mu \mathrm{M}$ ).

\section{Cell culture}

Rat pheochromocytoma PC12 cells were a kind gift from Professor A. Eckert (University of Basel, Basel, Switzerland). The cells were cultured in DMEM supplemented with $10 \%$ heat-inactivated fetal bovine serum, $5 \%$ heat-inactivated horse serum, $2 \mathrm{mM}$ L-glutamine, $50 \mathrm{U} / \mathrm{ml}$ penicillin, $50 \mathrm{mg} / \mathrm{ml}$ streptomycin in $5 \% \mathrm{CO}_{2}$ atmosphere at $37^{\circ} \mathrm{C}$.

\section{Cell treatment protocols}

Equal PC12 cell numbers were seeded into culture dishes, and after $24 \mathrm{~h}$ growth medium was changed to low-serum medium (DMEM supplemented with $2 \%$ heat-inactivated fetal bovine serum, $2 \mathrm{mM} \mathrm{L-glu-}$ tamine, $50 \mathrm{U} / \mathrm{ml}$ penicillin, $50 \mathrm{mg} / \mathrm{ml}$ streptomycin). Then, tested compounds were added to PC12 cells for 8-48 h. Freshly prepared sodium nitroprusside (SNP) at a concentration of $0.5 \mathrm{mM}$ was used as an inducer of oxidative stress and apoptosis. The appropriate controls with DMSO, as a vehicle, were also prepared.

\section{Determination of cell viability}

For analysis of the effect of treatment on the mitochondrial function and cell survival MTT assay was performed. After 24-48 h incubation in the presence of tested compounds, the medium was changed to serum-free DMEM, MTT $(0.25 \mathrm{mg} / \mathrm{ml})$ was added and cells were incubated for $2 \mathrm{~h}$. Then, medium was removed, cells were dissolved in DMSO and absorbance at $595 \mathrm{~nm}$ was measured on BioRad model 680 microplate reader.

\section{Determination of necrotic cell death}

For analysis of necrotic cell death LDH assay was performed by using commercial LDH-cytotoxicity Assay Kit II (BioVision, CA, USA). Shortly, after $24 \mathrm{~h}$ incubation in the presence of tested compounds, the whole medium was collected, mixed and centrifuged at $600 \times \mathrm{g}$ for $10 \mathrm{~min}$. Samples of supernatant were mixed with reaction buffer containing WST substrate and absorbance at $450 \mathrm{~nm}$ (reference $655 \mathrm{~nm}$ ) was measured every 5 min for 30 min on Bio-Rad model 680 microplate reader. Data from the linear increase phase were used for calculations.

\section{Determination of nitric oxide level by DAF-2 staining}

Measurement of the nitric oxide level was carried out using fluorescent indicator DAF-2 DA (Cayman Chemical Company). PC12 cells were loaded with $10 \mu \mathrm{M} \mathrm{DAF}-2$ in the presence of pluronic $(0.02 \%)$, 
washed, and incubated in pluronic-supplemented HBSS without (control) or with SNP (0.5 mM). DAF-2 fluorescence was measured after $8 \mathrm{~h}$.

\section{Analysis of gene expression by quantitative real time polymerase chain reaction ( $q R T P C R$ )}

Cultured cells were washed two times with icecold phosphate-buffered saline (PBS), scraped down and collected by centrifugation $(3 \mathrm{~min}, 1000 \times \mathrm{g}$ ). RNA was isolated with TRI-reagent and DNA remainings were digested with DNase I according to the manufacturer's protocols (Sigma-Aldrich). Quantity and purity of RNA was measured spectroscopically at 260 and $280 \mathrm{~nm}$ wave lengths. Reverse transcription was performed using High Capacity cDNA Reverse Transcription Kit according to the manufacturer's protocol (Applied Biosystems, Foster City, CA, USA). The level of mRNA for Polg was analyzed using SYBR Green JumpStart Taq ReadyMix, using the primer pair: forward 5'-CGGCTGACCTAATCCCTTTG-3', reverse 5'-CACTAACTGTTCCTGCCAATCCT-3'. The levels of mRNA for Ifng, 116 , Ptgs2, Alox 12 and Actb, as a reference gene, were analyzed using TaqMan Gene Expression Assays (Rn00594078_m1, Rn01410330_m1, Rn01483828_m1,Rn01461082and4352340E, respectively) and TaqMan Gene Expression Master Mix (Applied Biosystems). Plates were analyzed on $A B I$ PRISM 7500 apparatus (Applied Biosystems, Foster City, CA, USA). The relative levels of mRNA were calculated using the $\Delta \Delta C$ t method. Specificity of PCR reaction was verified by analyzing melting profiles - each profile contained only a single peak representing the specific product.

\section{Determination of DNA damage by TUNEL staining}

The presence of DNA damage in cells was determined by TdT-mediated dUTP-FITC nick end labelling (TUNEL) followed by flow cytometric detection. Shortly, after incubation in the presence of tested compounds for $12 \mathrm{~h}$, cells were fixed and stained by using APO-DIRECT Kit according to the manufacturer's protocol (BD Biosciences, San Jose, CA, USA). This method allows staining of damaged DNA by FITC, and total DNA with propidium iodide (PI). Samples were analysed on flow cytometer FACS Canto II.

\section{Determination of apoptosis by Hoechst 33342 staining}

The apoptotic body formation was determined by microscopic analysis of the cells stained with Hoechst 33342. Shortly, after $12 \mathrm{~h}$ incubation in the presence of tested compounds, the cells were fixed, stained and examined under a fluorescence microscope (Olympus BX51, Japan). Images were taken with a digital camera (Olympus DP70, Japan). A minimum of 200 cells/experimental group were counted in each experiment. Cells with typical apoptotic nuclear morphology (nuclear shrinkage, condensation) were identified as apoptotic and counted using randomly selected 30 fields for each experimental group. The results were expressed as \% of apoptotic cells according to the equation: \% of apoptotic cells $=($ apoptotic cells $) /$ (all cells $) \times 100$.

\section{Statistical analysis}

Data are expressed as mean values \pm S.E.M. Normality of distribution of individual variables was checked with Anderson-Darling normality test. Two group comparisons were done using Student's t-test. Multiple comparisons were analyzed by oneway analysis of variance ANOVA with Tukey posthoc test. Expression data for IFN- $\gamma$ and IL-6 are not normally distributed. Therefore, Kruskal-Wallis nonparametric test with Dunn's multiple comparisons post-hoc test was used to assess the statistical significance of obtained results. The statistical analyses were performed by using Graph Pad Prism version 5.0 (Graph Pad Software, San Diego, CA). Statistical significance was accepted at $p<0.05$.

\section{Results}

Our previous studies have shown that selected AFs isolated from $H$. selago and $D$. complanatum scavenge free radicals and effectively protect macromolecules from oxidative damage [7]. In the current study we investigate the possible cytoprotective properties of these compounds during oxidative stress in vitro. SNP, a donor of NO and other ROS, was used to generate oxidative stress and evoke cell death in PC12 cell line.

The initial aim was to define the optimal experimental conditions. First, we checked whether analyzed AFs possess any cytotoxic properties in our experimental system. The PC12 cells were incubated 
in the presence of AFs at concentration range 0.25 $6.25 \mu \mathrm{g} / \mathrm{ml}$ (approximately 1-25 $\mu \mathrm{M}$ ) for $24 \mathrm{~h}$ and $48 \mathrm{~h}$. It was found that after $24 \mathrm{~h}$ of incubation the AFs did not affect the viability of PC12 cells. Exclusively two fractions, AF2 and AF6 at a concentration $\geq 2.5 \mu \mathrm{g} / \mathrm{ml}$, exerted a cytotoxic effect when the time of incubation was increased to $48 \mathrm{~h}$ (Fig. 1A). To determine the optimal concentration of SNP to induce oxidative

\section{A}
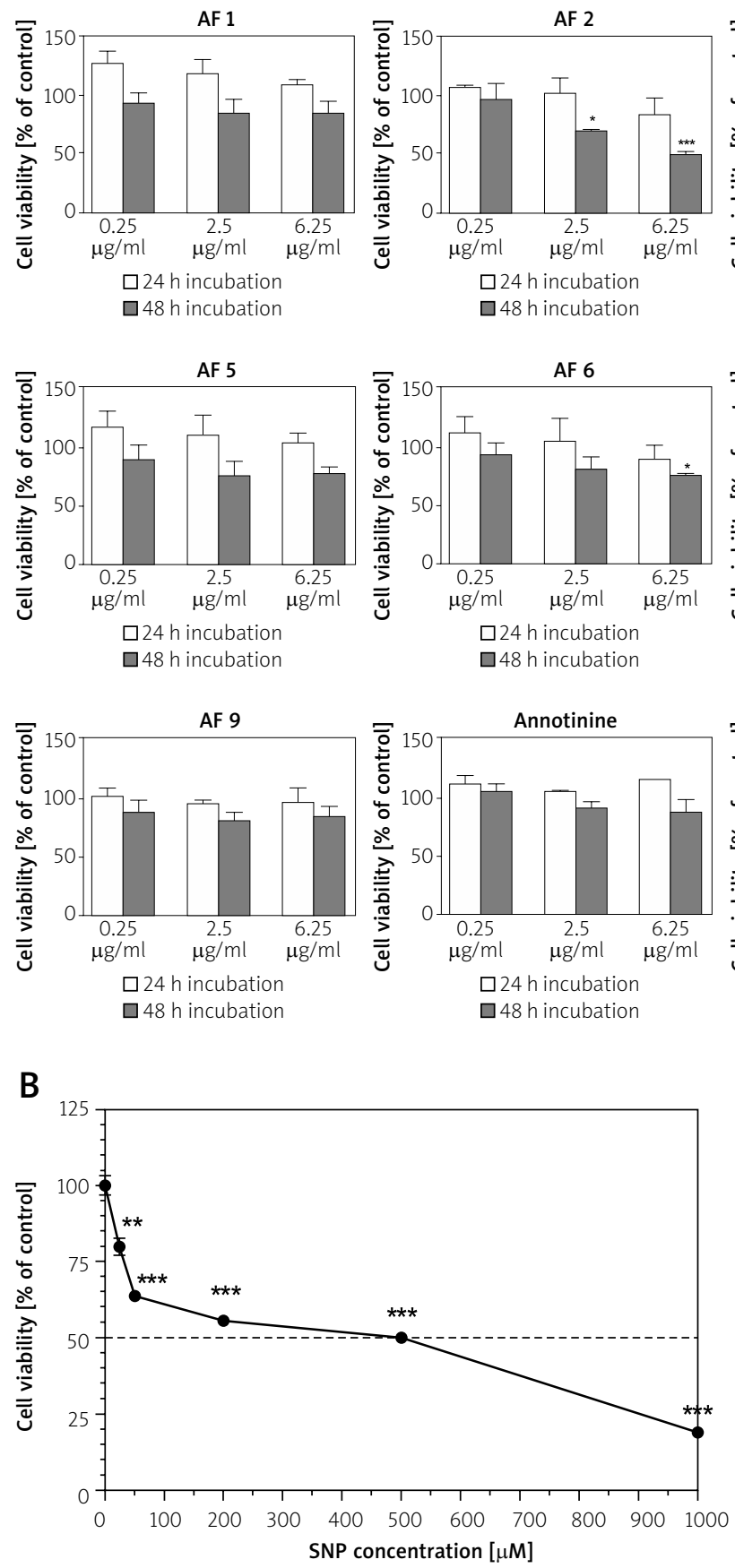

stress and cell death during $24 \mathrm{~h}$ treatment, cells were incubated in the presence of SNP in a concentration range of 25-1000 $\mu \mathrm{M}$. The results showed that SNP reduced PC12 cell viability. Exposure to $500 \mu \mathrm{M}$ SNP for $24 \mathrm{~h}$ decreased the viability of PC12 cells to $50 \%$ compared with the control group (Fig. 1B).

Therefore, further studies were carried out in the presence of AFs at $2.5 \mu \mathrm{g} / \mathrm{ml}$ (approximately
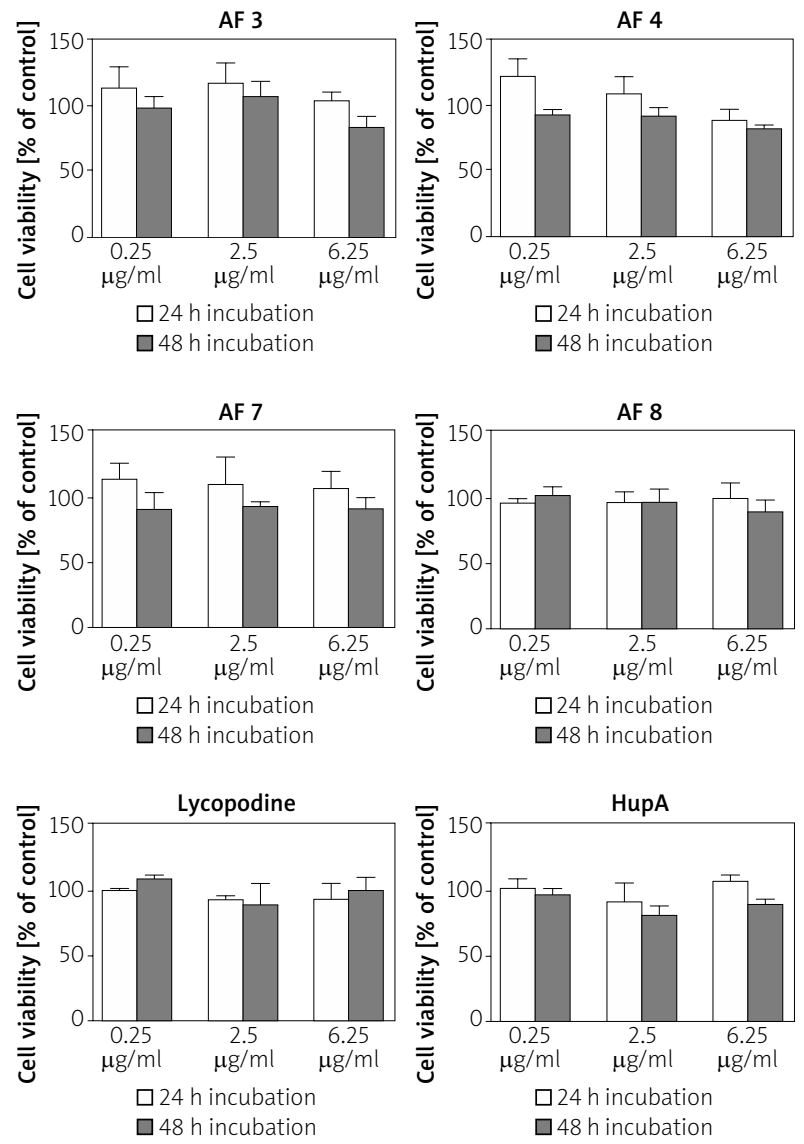

Fig. 1. The time-dependent effect of AFs or SNP on PC12 cell viability. PC12 cells were cultured in low-serum medium in the presence of AFs $(0.25-6.25 \mu \mathrm{g} / \mathrm{ml})$ for 24 or 48 hours (A) or SNP (25-1000 $\mu \mathrm{M})$ for 24 hours (B). Then, cell viability was determined by MTT assay. Results are the mean \pm SEM from three independent experiments. ${ }^{*} p<0.05,{ }^{* *} p<0.01,{ }^{* * *} p<0.001$, compared to control cells using Student $t$-test. 
$10 \mu \mathrm{M})$ concentration in oxidative stress evoked by incubation with $500 \mu \mathrm{M}$ SNP up to $24 \mathrm{~h}$. The MTT assay revealed that several AFs demonstrated the tendency to protect cells against SNP-evoked damage, whereas, a statistically significant effect was observed exclusively in the presence of two extract fractions, AF4 and AF5 (Fig. 2A). However, none of the compounds tested had any effect on SNP-

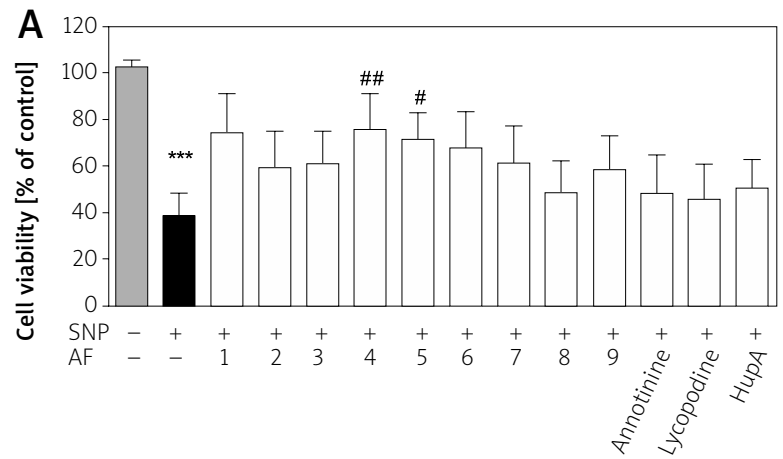

induced release of lactate dehydrogenase (LDH) (Fig. 2B). Based on this observation in further experiments we focused on AF4 and AF5.

To analyze the mechanism of cytoprotection evoked by AF4 and AF5 during SNP-induced stress, cells were incubated with SNP in the presence of AF4 and AF5 for $8 \mathrm{~h}$. The exposure of PC12 cells to SNP produced a marked increase in the NO level, as ana-

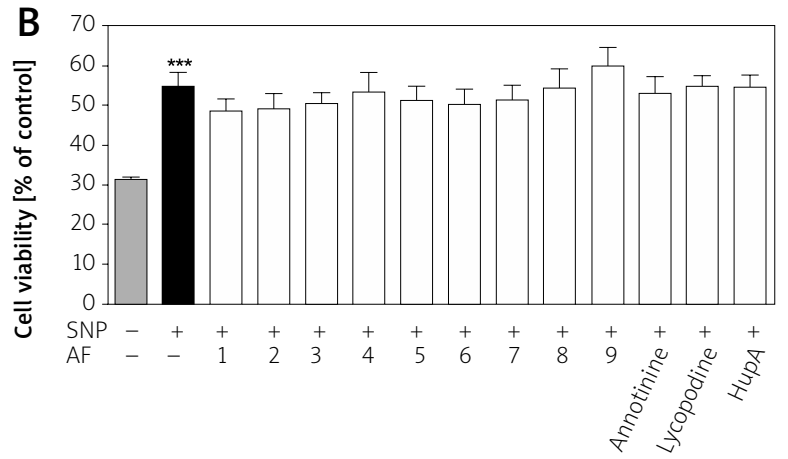

Fig. 2. The effect of AFs on SNP-evoked PC12 cell death. PC12 cells were cultured in low-serum medium in the presence of AFs $(2.5 \mu \mathrm{g} / \mathrm{ml})$ and SNP $(0.5 \mathrm{mM})$ for $24 \mathrm{~h}$. The effect of tested compounds on cell viability or necrotic cell death were analyzed using MTT assay (A) and LDH leakage assay (B), respectively. Data represent the mean value \pm SEM for 4 independent experiments. ${ }^{* *} p<0.001$, compared to control cells; ${ }^{*} p<0.05$, ${ }^{\#} p<0.01$, compared to SNP-treated cells using one-way ANOVA followed by the Tukey post-hoc test.

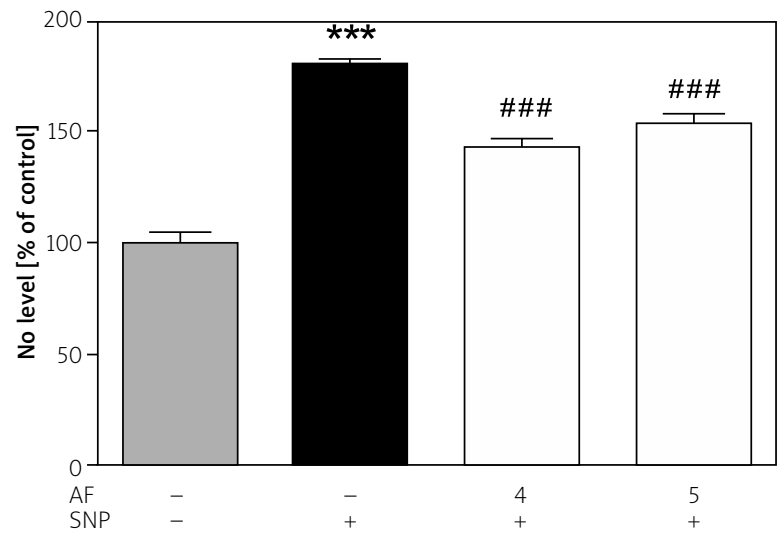

Fig. 3. The effect of AFs on SNP-evoked nitric oxide (NO) production. PC12 cells were loaded with $10 \mu \mathrm{M}$ DAF-2 in the presence of pluronic, washed, and incubated in pluronic-supplemented HBSS with AFs $(2.5 \mu \mathrm{g} / \mathrm{ml})$ and SNP $(0.5 \mathrm{mM})$. DAF-2 fluorescence was measured after $8 \mathrm{~h}$. Data represent the mean value \pm S.E.M. for 3 independent experiments. ${ }^{* * *} p<0.001$, compared to

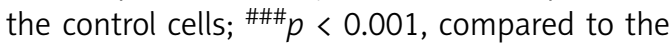
SNP-treated cells using a one-way ANOVA followed by the Tukey post-hoc test.

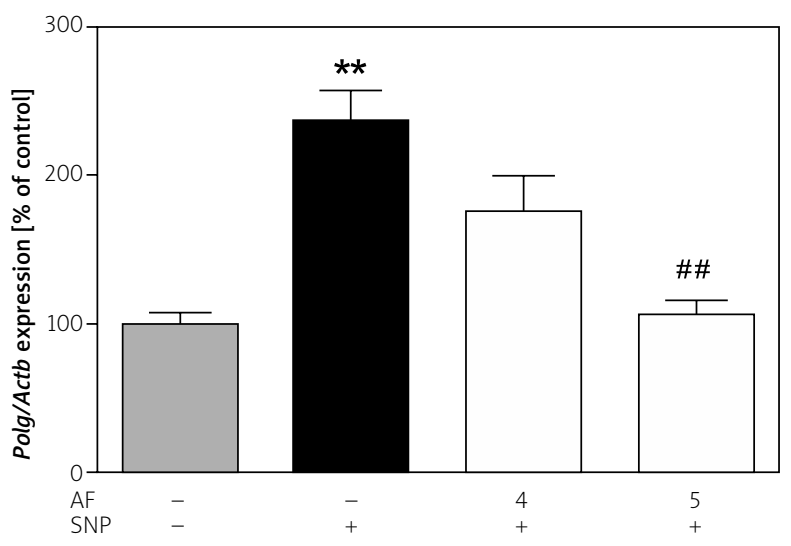

Fig. 4. The effect of AFs on SNP-evoked changes in Polg gene expression. PC12 cells were cultured in low-serum medium in the presence of AFs $(2.5 \mu \mathrm{g} / \mathrm{ml})$ and SNP $(0.5 \mathrm{mM})$ for $24 \mathrm{~h}$. The Polg gene expression was determined as described in the Methods section by qRT-PCR. Data represent the mean value \pm S.E.M. for 3 independent experiments. ${ }^{* *} p<0.01$, compared to the control cells; ${ }^{\# \#} p<0.01$, compared to the SNP-treated cells using a one-way ANOVA followed by the Tukey post-hoc test. 
A

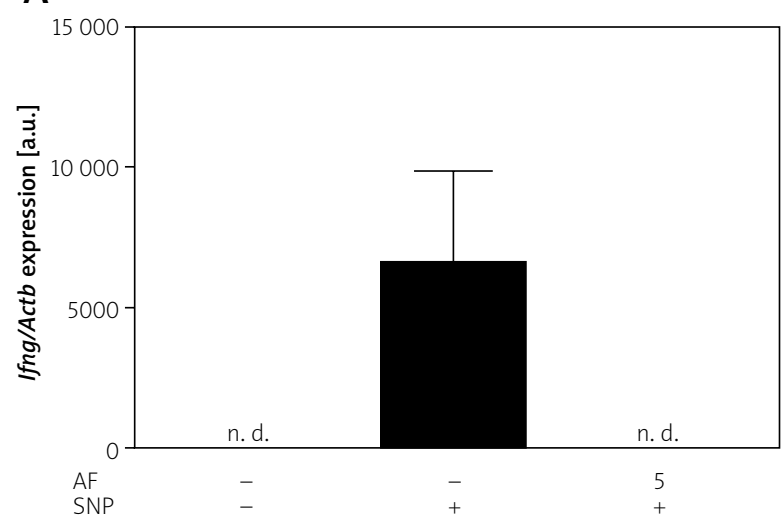

C

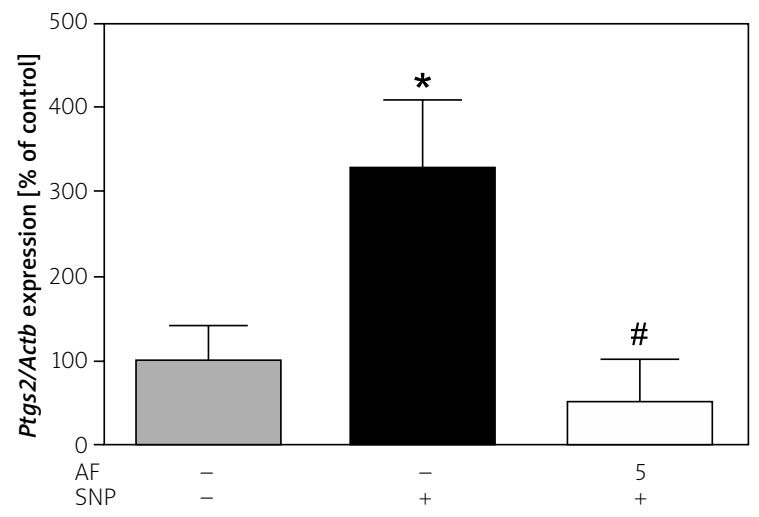

B

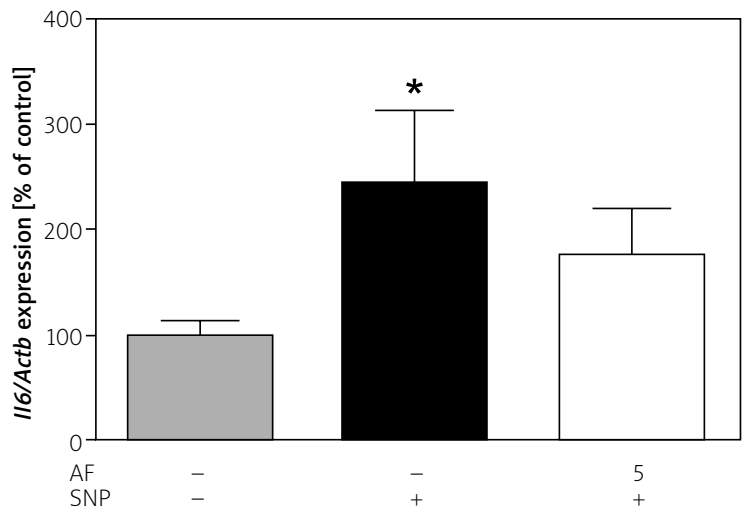

D

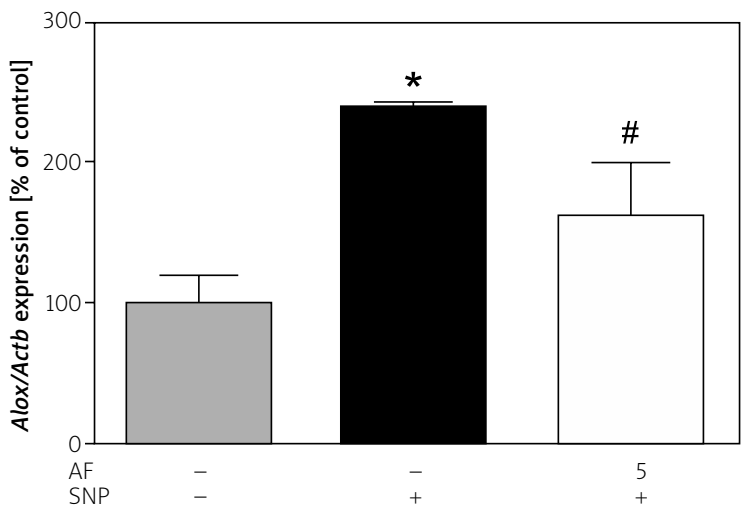

Fig. 5. The effect of AF on SNP-evoked changes in expression of genes encoding pro-inflammatory and pro-oxidative proteins. PC12 cells were cultured in low-serum medium in the presence of AF $(2.5 \mu \mathrm{g} / \mathrm{ml})$ and SNP $(0.5 \mathrm{mM})$ for $24 \mathrm{~h}$. The expression of genes encoding pro-inflammatory cytokines: IFN- $\gamma$ (A) and IL-6 (B) and pro-oxidative proteins: COX-2 (C) and 12/15-LOX (D) was determined as described in the Material and methods section by qRT-PCR. Data represent the mean value \pm S.E.M. for 3 independent experiments. ${ }^{*} p<0.05$, compared to the control cells; ${ }^{\#} p<0.05$, compared to the SNP-treated cells using nonparametric Kruskal-Wallis followed by Dunn's multiple comparisons post-hoc test or one-way ANOVA followed by Tukey post-hoc test for genes encoding cytokines and pro-oxidative proteins, respectively.

lysed by fluorogenic probe DAF-2. The co-treatment with AF4 or AF5 led to a significant decrease in the NO level, by about $20 \%$ and $15 \%$, respectively, when compared with the SNP-treated cells (Fig. 3). These data suggest that the possible mechanism of AF4 and/or AF5 action may be related to their NO-scavenging properties. Excessive amounts of $\mathrm{NO}$ and its metabolites are capable of altering gene expression as well as can impact the mitochondria function that is relevant to cell death. Here, we show that incubation of PC12 cells with SNP for $24 \mathrm{~h}$ evoked significant up-regulation of the expression of the gene for DNA polymerase $\gamma(P o l g)$ that is responsible for rep- lication of mitochondrial DNA and its repair processes (Fig. 4). In the presence of AF5, SNP did not increase the expression of Polg. Moreover, as shown in Figure 5, the expression of inflammation-related genes for IFN- $\gamma$ (Ifng), IL-6 (Il6), COX-2 (Ptgs2) and 12/15-LOX (Alox12) was increased in SNP-treated cells after $24 \mathrm{~h}$ incubation, comparing with the control group. AF5 completely protected cells against SNP-evoked induction of Ifng expression (Fig. 5A), significantly down-regulated the expression of Ptgs 2 and Alox 12 (Fig. 5C and D) and tends to decrease the mRNA level of $/ 16$ (Fig. 5B). AF4 had no effect on the SNP-evoked induction of inflammation-related genes (data not shown). 
A

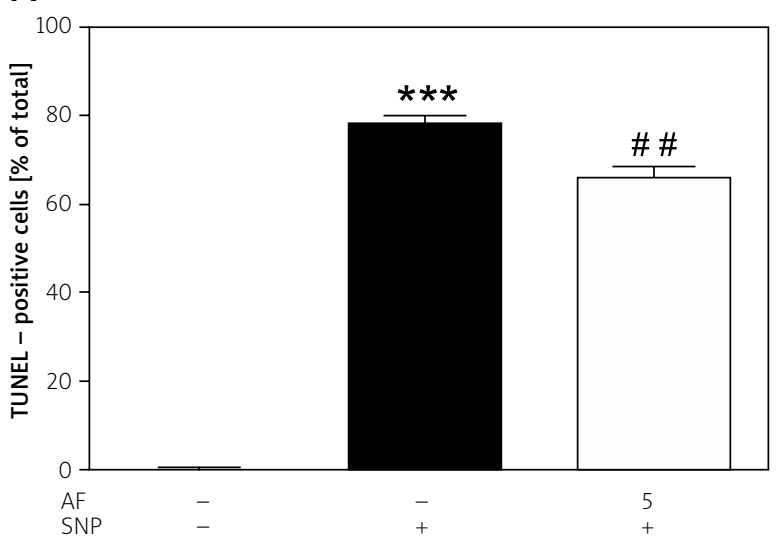

Fig. 6. The effect of AF on SNP-evoked DNA fragmentation. PC12 cells were cultured in a low-serum medium in the presence of $\mathrm{AF}(2.5 \mu \mathrm{g} / \mathrm{ml})$ and SNP $(0.5 \mathrm{mM})$ for $12 \mathrm{~h}$. The level of DNA fragmentation was determined as described in the Material and methods section by TUNEL method (A). Representative histograms of compared experimental groups are presented (B). Data represent the mean value \pm S.E.M. for 4 independent experiments. ${ }^{* * *} p<0.001$, compared to the control cells; ${ }^{\# \#} p<0.01$, compared to the SNP-treated cells using a one-way ANOVA followed by Tukey post-hoc test.
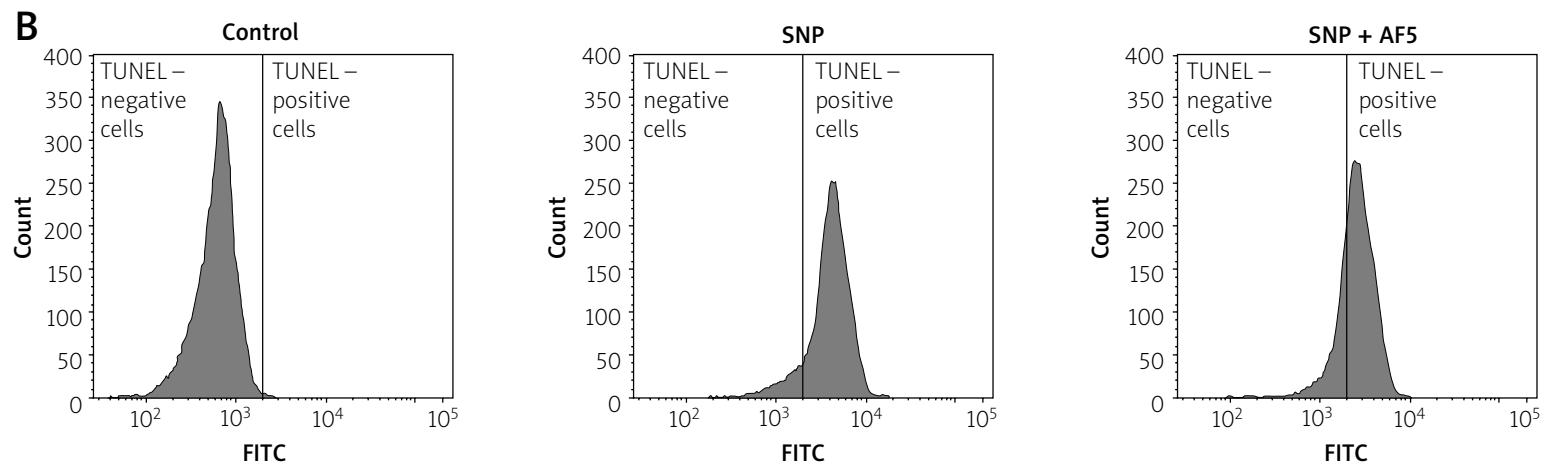

Furthermore, we analyzed the effect of AF5 on SNP-evoked loss of DNA integrity by using TUNEL method (TdT-mediated dUTP-FITC nick end labelling). SNP evoked an increase in the number of TUNEL-positive cells, indicating that the level of DNA fragmentation was elevated and AF5 reduced the percentage of cells classified as TUNEL-positive (Fig. 6A and B). The percentage of DNA fragmentation in PC12 cells exhibits a direct correlation with the percentage of apoptotic nuclei measured with Hoechst 33342 staining. SNP evoked typical hallmarks of apoptosis including chromatin aggregation and nuclear fragmentation, whereas AF5 effectively reduced SNPevoked apoptotic processes (Fig. 7A and B).

\section{Discussion}

Oxidative stress is recognized as an important component of the pathomechanism of several neurodegenerative disorders [15]. Therefore, in the last few years many studies focused on the search for new effective antioxidants with neuroprotective properties. Many plant extracts or even single compounds exert their protective effect via removal of free radicals or by the prevention of ROS generation. However, it appears that very often natural antioxidants, even if they show a beneficial protective effect in cell culture, have no or just limited effect in clinical trials [13]. Therefore, there is still an urgent need for new natural effective pharmaceuticals with antioxidant and cytoprotective properties. Our previous results indicated that alkaloid extracts from $H$. selago possess potent antioxidative properties, scavenge free radicals and prevent lipid and protein oxidation [13]. In the present work, the cytoprotective effects of alkaloid extracts from $H$. selago and D. complanatum on PC12 cells were tested. We found that the selected AFs, which were shown to have antioxidative properties, also exert a cytoprotective effect against SNP-induced oxidative stress.

Exposure to SNP in vitro partially mimics the oxidative stress observed in the brains of patients with neurodegenerative disorders [25, 27]. Excessive NO production plays a critical role in the pathomechanism of neurodegenerative and other neurological disorders. It has been shown that in degenerative conditions characterized by oxidative stress, 


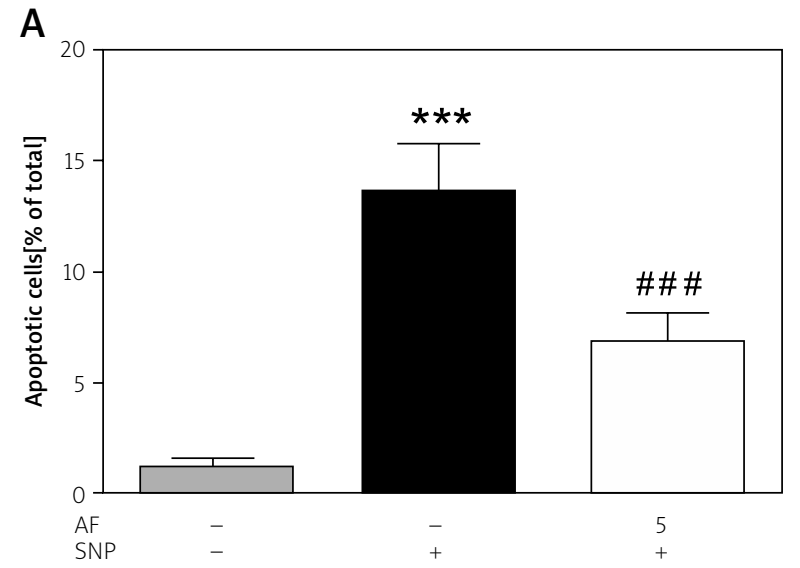

B
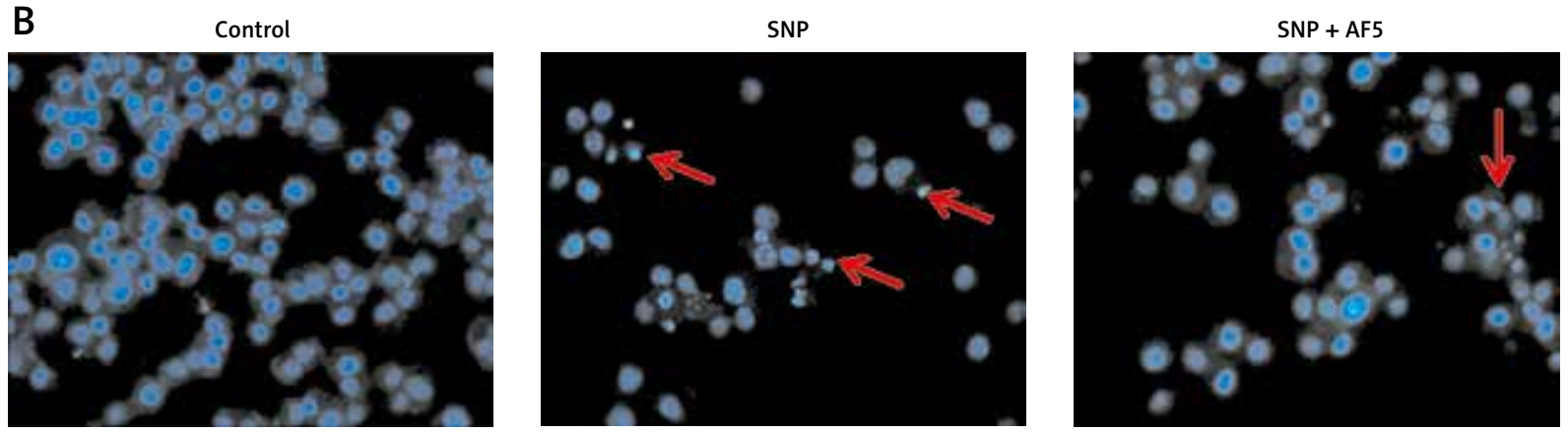

Fig. 7. The effect of AF on SNP-evoked apoptosis. PC12 cells were cultured in a low-serum medium in the presence of AF $(2.5 \mu \mathrm{g} / \mathrm{ml})$ and SNP $(0.5 \mathrm{mM})$ for $12 \mathrm{~h}$. The level of apoptosis was determined as described in the Material and methods section by Hoechst staining (A). Representative images are presented (B). Red arrows indicate nuclei with typical apoptotic features. Data represent the mean value \pm S.E.M. for 4 independent experiments. ${ }^{* * *} p<0.001$, compared to the control cells; ${ }^{* \#} p<0.001$, compared to the SNP-treated cells using a one-way ANOVA followed by Tukey post-hoc test. increased levels of NO lead to aberrant S-nitrosylation of proteins that contributes to the pathology of the disease [25]. Excessive liberation of NO and enhanced S-nitrosylation affects the mitochondrial function, proteostasis, transcriptional regulation, synaptic activity, and cell survival [26]. In the present work, the level of intracellular NO in PC12 cells was remarkably increased by SNP. However, cotreatment with AF4 or AF5 led to a reduction in the NO level. In the previous work we identified components of fractions AF4 and AF5. AF4 contains 6- $\beta$-hydroxyhuperzine, Huperzine $A$, Huperzine $B$, Lycoposerramine-L or Lycoposerramine- $M$, Lycopodine, Lycoposerramine-G, probable 8b-Hydroxylycoposerramine $\mathrm{K}$ and Lyconadin [13]. The identified components of AF5 were Lycopodine, Serratidine, Lycoposerramine-G and probably Cermizine B [7]. Therefore, these alkaloids might be responsible for antioxidative and cytoprotective properties of analyzed fractions. An elevated NO level induces mitochondrial failure including alterations in calcium homeostasis, mitochondrial energy, ROS generation and promotes mitochondrial DNA damage [3].
Because polymerase $\gamma$ is the only DNA polymerase present in mitochondria, it is necessarily implicated in all DNA repair processes, therefore activation of this enzyme is considered as an indicator of mitochondrial DNA damage. In the present study we suggest that SNP evokes mitochondrial DNA damage leading to polymerase $\gamma$ activation for DNA repair. Activation of this enzyme was not observed in the presence of AF5 fraction, indicating that components of AF5 effectively protected PC 12 cells against SNP-induced mitochondrial injury. Till now, cytoprotective potential of these specific compounds has not been tested.

Oxidative stress affects many cellular signaling pathways, including alterations of gene expression, for example activation of transcription of inflammation-related IFN- $\gamma$, IL-6, IL-1 $\beta$, and TNF- $\alpha$ [23]. Our work showed that AF5 attenuated transcription of inflammation-related genes activated by oxidative stress. AF5 completely prevented the SNP-evoked induction of Ifng and tends to down-regulate the expression of 116 in PC12 cells. Down-regulation of pro-oxidative/pro-inflammatory genes could be 
an important mechanism of cytoprotection, because the inflammatory processes are involved in the pathomechanism of a wide range of neurodegenerative diseases, including AD and PD [9]. Especially intriguing is the effect of AF5 on expression of genes Ptgs2 and Alox 12, which contribute to synthesis of arachidonic acid (AA)-derived lipid mediators. Arachidonic acid is a free fatty acid that is released from the cell membrane in response to various stimuli [21]. There are two most important families of enzymes involved in the oxidative metabolism of $A A$, lipoxygenases (LOXs), which produce leukotrienes and the cyclooxygenases (COXs) COX-1 and COX-2, which produce prostaglandins. Recent work has highlighted the potential role of $12 / 15$-LOX as well as COX-2 in the pathogenesis of neurodegenerative disorders [6]. Modulation of the expression and activity of LOX and COX might offer an effective disease-modifying strategy for therapy of neurodegenerative disorders. In the current study, we found that cell treatment with AF5 prevented SNP-induced upregulation of Alox 12 as well as Ptgs 2 expression. These data are in agreement with those obtained by Wang et al., who showed that Huperzine A, an alkaloid compound found primarily in other firmoss, $H$. serrata, suppressed overexpression of inflammatory genes and improved learning and memory in rats [37]. Moreover, a lot of other alkaloids demonstrated significant anti-inflammatory properties [35]. The fragmentation of DNA is one of the most characteristic phenomena of apoptosis [34]. TUNEL assay, which was initially developed to detect apoptosis-related DNA degradation, labels DNA strand breaks, including the $3^{\prime} \mathrm{OH}$ termini of single strand breaks and all forms of double strand breaks. Therefore, it may indicate also other types of DNA degradation, for example evoked by oxidative damage. Here, using TUNEL method we showed that SNP induced DNA fragmentation and AF5 reduced the percentage of cells with damaged DNA. To specifically detect apoptotic fragmentation of DNA we used Hoechst 33342 staining, which allows identifying late apoptotic cells by morphological characterization of typical changes in nuclear chromatine aggregation and fragmentation. Our data indicated that SNP significantly increased the number of apoptotic cells, and AF5 efficiently reduced the number of cells with apoptotic morphology.

In conclusion, our data demonstrated that only selected alkaloid fractions of $H$. selago contain some compounds having potent cytoprotective properties. They might be particularly promising compounds for discovering and developing novel clinical drugs in the treatment of neurodegenerative disorders.

\section{Acknowledgments}

Financial support was provided by National Science Centre Grant no. 2012/05/B/NZ3/ 02047 and by the project "Advanced methods, pharmaceuticals and therapies for health protection and economy in the $21^{\text {st }}$ century: interdisciplinary studies in biomedical sciences at university second and third level", no. POKL.04.03.00-00-060/12. The project was co-financed by the European Union from the European Social Fund under the Operational Programme Human Capital, and by a grant from the Polish Ministry of Science and Higher Education, grant no. NN 405362237.

\section{Disclosure}

Authors report no conflict of interest.

\section{References}

1. Adamczyk A, Kazmierczak A, Czapski GA, Strosznajder JB. $\alpha$-Synuclein induced cell death in mouse hippocampal (HT22) cells is mediated by nitric oxide-dependent activation of caspase-3. FEBS Lett 2010; 584: 3504-3508.

2. Bazinet RP, Layé S. Polyunsaturated fatty acids and their metabolites in brain function and disease. Nat Rev Neuro 2014; 15: 771-785.

3. Bolaños JP, Almeida A, Stewart V, Peuchen S, Land JM, Clark JB, Heales SJR. Nitric Oxide-Mediated Mitochondrial Damage in the Brain: Mechanisms and Implications for Neurodegenerative Diseases. J Neurochem 1997; 68: 2227-2240.

4. Bournival J, Quessy P, Martinoli MG. Protective Effects of Resveratrol and Quercetin Against MPP+-Induced Oxidative Stress Act by Modulating Markers of Apoptotic Death in Dopaminergic Neurons. Cell Mol Neurobiol 2009; 29: 1169-1180.

5. Czapski GA, Avram D, Sakharov DV, Wirtz KW, Strosznajder JB, Pap EHW. Activated neutrophils oxidize extracellular proteins of endothelial cells in culture: effect of nitric oxide donors. Biochem J 2002; 365: 897-902.

6. Czapski GA, Gassowska M, Wilkaniec A, Chalimoniuk M, Strosznajder JB, Adamczyk A. The mechanisms regulating cyclindependent kinase 5 in hippocampus during systemic inflammatory response: The effect on inflammatory gene expression. Neurochem Int 2016; 93: 103-112.

7. Czapski G, Szypula W, Kudlik M, Wilenska B, Kania M, Danikiewicz W, Adamczyk A. Assessment of antioxidative activity of alkaloids from Huperzia selago and Diphasiastrum complanatum using in vitro systems. Folia Neuropathol 2014; 52: 1-13. 
8. Dixon SJ, Stockwell1 BR. The role of iron and reactive oxygen species in cell death. Nat Chem Biol 2014; 10: 9-17.

9. Ferencik M, Novak M, Rovensky J, Rybar I. Alzheimer's disease inflammationand non-steroidalanti-inflammatorydrugs. Bratisl Lek Listy 2001; 102: 123-132.

10. Fu XY, Yang MF, Cao MZ, Li DW, Yang XY, Sun JY, Zhang ZY, Mao LL, Zhang S, Wang FZ, Zhang F, Fan CD, Sun BL. Strategy to Suppress Oxidative Damage-Induced Neurotoxicity in PC12 Cells by Curcumin: the Role of ROS-Mediated DNA Damage and the MAPK and AKT Pathways. Mol Neurobiol 2014; 53: 369-378.

11. Gao X, Tang XC. Huperzine A attenuates mitochondrial dys function in beta-amyloid-treated PC12 cells by reducing oxygen free radicals accumulation and improving mitochondrial energy metabolism. J Neurosci Res 2006; 83: 1048-1057.

12. Gülçin I. Antioxidant activity of caffeic acid (3,4-dihydroxycinnamic acid). Toxicology 2006; 217: 213-220.

13. Halliwell B. Free radicals and antioxidants - quo vadis? Trends Pharmacol Sci 2011; 32: 125-130.

14. Jang $J \mathrm{H}$, Surh YJ. Protective effect of resveratrol on $\beta$-amyloid-induced oxidative PC12 cell death. Free Radic Biol Med 2003; 34 1100-1110.

15. Kim GH, Kim JE, Rhie SJ, Yoon S. The Role of Oxidative Stress in Neurodegenerative Diseases. Exp Neurobiol 2015; 24: 325-340.

16. Kim J, Lee HJ, Lee KW. Naturally occurring phytochemicals for the prevention of Alzheimer's disease. J Neurochem 2010; 112 1415-1430

18. Koh SH, Kwon H, Park KH, Ko JK, Kim JH, Hwang MS, Yum YN Kim OH, Kim J, Kim HT, Do BR, Kim KS, Kim H, Roh H, Yu HJ, Jung HK, Kim SH. Protective effect of diallyl disulfide on oxidative stress-injured neuronally differentiated PC12 cells. Brain Res Mol Brain Res 2005; 133: 176-186.

19. Li J, O W, Li W, Jiang ZG, Ghanbari HA. Oxidative Stress and Neurodegenerative Disorders. Int J Mol Sci 2013; 14: 24438 24475.

20. Lin YH, Liu AH, Wu HL, Westenbroek C, Song QL, Yu HM, Ter Horst GJ, Li XJ. Salvianolic acid B, an antioxidant from Salvia miltiorrhiza, prevents Abeta(25-35)-induced reduction in BPRP in PC12 cells. Biochem Biophys Res Commun 2006; 348: 593-599.

21. Liscovitch M. Crosstalk among multiple signal-activated phos pholipases. Trends Biochem Sci 1992; 17: 393-399.

22. Ma X, Gang DR. The Lycopodium alkaloids. Nat Prod Rep 2004 ; 21: 752-772.

23. Mukhopadhyay P, Rajesh M, Horváth B, Bátkai S, Park O, Tanchian G, Gao RY, Patel V, Wink DA, Liaudet L, Haskóe G, Mechoulamf R, Pachera P. Cannabidiol protects against hepatic ischemia/reperfusion injury by attenuating inflammatory sig naling and response, oxidative/nitrative stress, and cell death. Free Radic Biol Med 2011; 50: 1368-1381.

24. Muthaiyah B, Essa MM, Chauhan V, Chauhan A. Protective effects of walnut extract against amyloid beta peptide induced cell death and oxidative stress in PC12 cells. Neurochem Res 2011; 36: 2096-2103.

25. Nakamura T, Prikhodko OA, Pirie E, Nagar S, Akhtar MW, Oh CK, McKercher SR, Ambasudhan R, Okamoto S, Lipton SA. Aberrant protein S-nitrosylation contributes to the pathophysiology of neurodegenerative diseases. Neurobiol Dis 2015; 84: 99-108.
26. Nakamura T, Lipton SA. Protein S-Nitrosylation as a Therapeutic Target for Neurodegenerative Diseases. Trends Pharmacol Sci 2016; 37: 73-84.

27. Pytlowany $M$, Strosznajder JB, Jęśko $H$, Cąkała $M$, Strosznajder RP. Molecular mechanism of PC12 cell death evoked by sodium nitroprusside, a nitric oxide donor. Acta Biochim Pol 2008; 55: 339-347.

28. Rajendran P, Nandakumar N, Rengarajan T, Palaniswami R, Gnanadhas EN, Lakshminarasaiah U, Gopas J, Nishigaki I. Antioxidants and human diseases. Clin Chim Acta 2014; 436: 332347.

29. Ramalingam M, Kim SJ. Reactive oxygen/nitrogen species and their functional correlations in neurodegenerative diseases. J Neural Transm 2012; 119: 891-910.

30. Ramassamy C. Emerging role of polyphenolic compounds in the treatment of neurodegenerative diseases: A review of their intracellular targets. Eur J Pharmacol 2006; 545: 51-64.

31. Ray PD, Huang BW, Tsuji Y. Reactive oxygen species (ROS) homeostasis and redox regulation in cellular signaling. Cell Signal 2012; 24: 981-990.

32. Ruszkiewicz J, Albrecht J. Changes in the mitochondrial antioxidant systems in neurodegenerative diseases and acute brain disorders. Neurochem Int 2015; 88: 66-72.

33. Sarna LK, Wu N, Hwang SY, Siow YL, Karmin O. Berberine inhibits NADPH oxidase mediated superoxide anion production in macrophages. Can J Physiol Pharmacol 2010; 88: 369-378.

34. Silva A, Gomes O. Oxidative DNA damage protection and repair by polyphenolic compounds in PC12 cells. Eur J Pharmacol 2008; 601: 50-60.

35. Souto AL, Tavares JF, da Silva MS, Diniz Mde F, de AthaydeFilho PF, Barbosa Filho JM. Anti-inflammatory activity of alkaloids: an update from 2000 to 2010. Molecules 2011; 16: 8515 8534.

36. Szypula W, Pietrosiuk A, Suchocki P, Olszowska O, Furmanowa M, Kazimierska O. Somatic emryogenesis and in vitro culture of Huperzia selago shoots as a potential source of huperzine A. Plant Sci 2005; 168: 1443-1452.

37. Wang J, Zhang HY, Tang XC. Huperzine a improves chronic inflammation and cognitive decline in rats with cerebral hypoperfusion. J Neurosci Res 2010; 88: 807-815.

38. Wilkaniec A, Strosznajder JB, Adamczyk A. Toxicity of extracellular secreted alpha-synuclein: Its role in nitrosative stress and neurodegeneration. Neurochem Int 2013; 62: 776-783.

39. Xiao H, LV F, Xu W, Zhang L, Jing P, Cao X. Deprenyl prevents MPP-induced oxidative damage in PC12 cells by the upregulation of Nrf2-mediated NQO1 expression through the activation of PI3K/Akt and Erk. Toxicology 2011; 290: 286-294.

40. Zhang HY, Tang XC. Neuroprotective effects of huperzine A: new therapeutic targets for neurodegenerative disease. Trends Pharmacol Sci 2006; 27: 619-625.

41. Zhang S, Ye J, Dong G. Neuroprotective effect of baicalein on hydrogen peroxide-mediated oxidative stress and mitochondrial dysfunction in PC12 cells. J Mol Neurosci 2010; 40: 311-320. 